\title{
Governança corporativa e fenomenografia: revisão de literatura e proposição de abordagem teórico-metodológica
}

\section{Corporate governance and phenomenography: literature review and proposition of an theoretical-methodological approach}

\author{
CARLOS FREDERICO TREVIA \\ Pontifícia Universidade Católica do Rio de Janeiro \\ LEANDRO SCHOEMER JARDIM \\ Pontifícia Universidade Católica do Rio de Janeiro \\ SANDRA REGINA DA ROCHA-PINTO \\ Pontifícia Universidade Católica do Rio de Janeiro
}

\section{RESUMO:}

campo da Governança Corporativa vem sendo objeto de estudos organizacionais que indicam a necessidade de novas perspectivas teóricas e metodológicas a serem consideradas em pesquisas na área. Esse interesse foi identificado em uma revisão da literatura sobre Governança Corporativa, com foco em identificar consolidações de discussões teóricas e metodológicas na área. Este artigo discute uma abordagem de pesquisa qualitativa e interpretativa que pode contribuir tanto para a evolução das teorias quanto para o desenvolvimento desta prática organizacional. Constatou-se que a prática de Governança Corporativa pode ser considerada como um sistema contextualizado, dinâmico e aberto, tornando o campo propenso à proposição da fenomenografia como uma abordagem teórico-metodológica, a qual se verificou que possui as características que atendem às necessidades de pesquisa, podendo gerar resultados inovadores.

Palavras-chave: Governança, Organizações, Fenomenografia, Prática, Tomada de Decisão. 


\section{Abstract:}

The field of Corporate Governance has been the subject of organizational studies that indicate the need for new theoretical and methodological perspectives to be considered in research in the area. This interest was identified in a review of the literature on Corporate Governance, with a focus on identifying consolidations of theoretical and methodological discussions in the area. This article discusses a qualitative and interpretative research approach that can contribute both to the evolution of theories and to the development of this organizational practice. It was verified that the practice of Corporate Governance can be considered as a contextualized, dynamic and open system, making the field prone to the proposition of phenomenology as a theoretical-methodological approach, which has been found to possess the characteristics that meet the research needs, and can generate innovative results.

Keywords: Governance, Organizations, Phenomenography, Practice, Decision Taking.

\section{INTRODUÇÃo}

Diversos problemas éticos e de má gestão, vistos em jornais, têm sido combatidos por mecanismos de Governança Corporativa que são criados e propostos por empresas, institutos técnicos especializados, órgãos reguladores ou por força legal. Esse esforço de melhorar os sistemas de Governança Corporativa tem ocorrido com mais intensidade desde 2002, após escândalos envolvendo grandes empresas nos Estados Unidos, e, mais recentemente, desde 2014 no Brasil, com a divulgação de escândalos de corrupção que expuseram a Governança Corporativa das grandes empresas, incluindo empresas de capital aberto, sujeitas a pressões externas.

Há uma concentração de publicações no Brasil em Governança Corporativa sobre questões referentes à legislação e à regulação, dimensões relacionadas a aspectos de controle (LEITE et al., 2013). Outras dimensões, como estratégia, responsabilidade social, cultura, recursos humanos, aspectos comportamentais e a ética são praticamente inexploradas no Brasil. Com a expansão da área de estudo no campo da Governança Corporativa, novas perspectivas teóricas e metodológicas estão se tornando necessárias. 
Assim, este artigo discute, com base na revisão de literatura realizada, o emprego da fenomenografia (MARTON, 1986; 1981; MARTON e BOOTH, 1997), uma abordagem teórico-metodológica qualitativa e interpretativa, na pesquisa em estudos organizacionais no campo da Governança Corporativa. As características dessa abordagem, se pode defender, atendem às necessidades atuais dos pesquisadores na área.

O artigo está dividido em seis seções, a primeira esta introdução; a segunda a metodologia; na terceira seção, uma análise da revisão de literatura, dividida em perspectivas teóricas e metodológicas no campo; a quarta seção discute os resultados; a quinta apresenta a fenomenografia como proposta de abordagem para o campo; e, por fim, a sexta seção, com as considerações finais.

\section{Metodologia}

Foi realizada uma revisão de literatura em artigos revisados por pares em publicações listadas em uma base relevante (Base Scopus), em áreas temáticas relacionadas (Gestão, Negócios e Contabilidade, Ciências Sociais, Ciências Decisórias e Economia, Econometria e Finanças) à despeito de fator de impacto, limitando à termos definidos pelos autores, de modo a buscar consolidações de discussões teóricas e metodológicas em Governança Corporativa, além de artigos adicionais conhecidos pelos autores, sendo reduzida posteriormente a lista encontrada por meio da leitura dos títulos e resumos de modo a selecionar consolidações contendo discussões teóricas e metodológicas, como pretendido, à exemplo da abordagem de McNulty, Zattoni e Douglas (2013, pp. 184-185).

A busca se deu por artigos com 'Governança Corporativa' no título e indicando em seus resumos a realização de bibliometrias, meta-análises e revisões de literatura, no período de publicação de 2002 a 2017. Obtiveram-se, assim, 312 artigos. De modo a focar nos processos internos, foram retirados artigos sobre: especificidades de países; empresas familiares; instituições não-governamentais sem fins lucrativos; resultados e questões financeiras; e questões legais, chegando-se a 15 artigos. Foi realizada uma revisão complementar na Revista 'Corporate Governance International Review' (1 artigo editorial) e, a partir do conhecimento dos autores, foram incluídos 
mais 3 artigos que não constam da Base Scopus, totalizando 19 artigos revisados (Tabela 1). Os quatro artigos complementares estão indicados na Tabela 1.

Tabela1 - Revisões de Literatura sobre Governança Corporativa no mundo de 2002 a 2017

\begin{tabular}{|c|c|c|}
\hline Publicação & Título & Autor (ano) \\
\hline $\begin{array}{l}\text { Corporate Governance } \\
\text { International Review }\end{array}$ & $\begin{array}{l}\text { Methodological Rigor of Cor- } \\
\text { porate Governance Studies: } \\
\text { A Review and Recommenda- } \\
\text { tions for Future Studies }\end{array}$ & $\begin{array}{l}\text { Boyd et al. } \\
(2017)\end{array}$ \\
\hline $\begin{array}{l}\text { Corporate Governance } \\
\text { International Review } \\
\text { (Complementar - Base } \\
\text { Scopus) }\end{array}$ & $\begin{array}{l}\text { Methodological Issues in Gov- } \\
\text { ernance Research: An Editor's } \\
\text { Perspective }\end{array}$ & $\begin{array}{l}\text { Filatotchev } \\
\text { e Wright } \\
\text { (2017) }\end{array}$ \\
\hline $\begin{array}{l}\text { International Journal of } \\
\text { Law and Management }\end{array}$ & $\begin{array}{l}\text { Basic Corporate Governance } \\
\text { Models: A Systematic Review }\end{array}$ & $\begin{array}{l}\text { Ahmad } \\
\text { e Omar } \\
(2016)\end{array}$ \\
\hline $\begin{array}{l}\text { Management and Organi- } \\
\text { zation Review }\end{array}$ & $\begin{array}{l}\text { Empirical Research on Corpo- } \\
\text { rate Governance in China: A } \\
\text { Review and New Directions } \\
\text { for the Future }\end{array}$ & $\begin{array}{l}\text { Shen et al. } \\
(2016)\end{array}$ \\
\hline $\begin{array}{l}\text { European Journal of Sci- } \\
\text { entific Research (Comple- } \\
\text { mentar - Outras Bases) }\end{array}$ & $\begin{array}{l}\text { Theoretical Perspective of Cor- } \\
\text { porate Governance: A Review }\end{array}$ & $\begin{array}{l}\text { Afza e Na- } \\
\text { zir }(2014)\end{array}$ \\
\hline Universiti Putra Malaysia & $\begin{array}{l}\text { Review of Corporate Gover- } \\
\text { nance Bundle }\end{array}$ & $\begin{array}{l}\text { Al-Baid- } \\
\text { hani }(2014)\end{array}$ \\
\hline $\begin{array}{l}\text { Asia Pacific Journal Man- } \\
\text { agement }\end{array}$ & $\begin{array}{l}\text { Corporate Governance and } \\
\text { National Institutions: A Re- } \\
\text { view and Emerging Research } \\
\text { Agenda }\end{array}$ & $\begin{array}{l}\text { Filatotchev } \\
\text { et al. (2013) }\end{array}$ \\
\hline $\begin{array}{l}\text { Corporate Governance: } \\
\text { An International Review }\end{array}$ & $\begin{array}{l}\text { Developing Corporate Gov- } \\
\text { ernance Research Through } \\
\text { Qualitative Methods: A Re- } \\
\text { view of Previous Studies }\end{array}$ & $\begin{array}{l}\text { McNulty et } \\
\text { al. (2013) }\end{array}$ \\
\hline $\begin{array}{l}\text { International Research } \\
\text { Journal of Finance and } \\
\text { Economics }\end{array}$ & $\begin{array}{l}\text { Corporate Governance: A } \\
\text { Summary Review on Different } \\
\text { Theory Approaches }\end{array}$ & $\begin{array}{l}\text { Ping e } \\
\text { Andy } \\
(2011)\end{array}$ \\
\hline
\end{tabular}




\begin{tabular}{|c|c|c|}
\hline Publicação & Título & Autor (ano) \\
\hline $\begin{array}{l}\text { African Journal of Busi- } \\
\text { ness Management } \\
\text { (Complementar - Outras } \\
\text { Bases) }\end{array}$ & $\begin{array}{l}\text { Historical Research on Corpo- } \\
\text { rate Governance: A Bibliomet- } \\
\text { ric Analysis }\end{array}$ & $\begin{array}{l}\text { Huang e } \\
\text { Ho (2011) }\end{array}$ \\
\hline Accounting and Finance & $\begin{array}{l}\text { Corporate Governance, Ac- } \\
\text { counting and Finance: A } \\
\text { Review }\end{array}$ & $\begin{array}{l}\text { Brown et } \\
\text { al. }(2011)\end{array}$ \\
\hline $\begin{array}{l}\text { Corporate Governance: } \\
\text { The International Journal } \\
\text { of Business in Society }\end{array}$ & $\begin{array}{l}\text { A Review of Latin American } \\
\text { Corporate Governance Litera- } \\
\text { ture: } 2000-2009\end{array}$ & $\begin{array}{l}\text { Harris } \\
(2009)\end{array}$ \\
\hline $\begin{array}{l}\text { Corporate Governance: } \\
\text { An International Review }\end{array}$ & $\begin{array}{l}\text { Taking Stock of Corporate } \\
\text { Governance Research While } \\
\text { Looking to the Future }\end{array}$ & $\begin{array}{l}\text { Filatotchev } \\
\text { e Boyd } \\
(2009)\end{array}$ \\
\hline $\begin{array}{l}\text { Corporate Governance: } \\
\text { An International Review }\end{array}$ & $\begin{array}{l}\text { Maturation of Corporate Gov- } \\
\text { ernance Research, 1993-2007: } \\
\text { An Assessment }\end{array}$ & $\begin{array}{l}\text { Durisin } \\
\text { e Puzone } \\
(2009)\end{array}$ \\
\hline $\begin{array}{l}\text { Corporate Ownership; } \\
\text { Control }\end{array}$ & $\begin{array}{l}\text { Theoretical Foundations of } \\
\text { Corporate Governance Revis- } \\
\text { ited: A Critical Review }\end{array}$ & $\begin{array}{l}\text { Duhnfort et } \\
\text { al. (2008) }\end{array}$ \\
\hline $\begin{array}{l}\text { Journal of Management } \\
\text { Studies }\end{array}$ & $\begin{array}{l}\text { Corporate Governance in } \\
\text { Emerging Economies: A Re- } \\
\text { view of the Principal-Principal } \\
\text { Perspective }\end{array}$ & $\begin{array}{l}\text { Young et } \\
\text { al. }(2008)\end{array}$ \\
\hline $\begin{array}{l}\text { Accounting, Auditing and } \\
\text { Accountability Journal }\end{array}$ & $\begin{array}{l}\text { Corporate Governance, Ac- } \\
\text { countability and Mechanisms } \\
\text { of Accountability: An Over- } \\
\text { view }\end{array}$ & $\begin{array}{l}\text { Brennan e } \\
\text { Solomon } \\
(2008)\end{array}$ \\
\hline $\begin{array}{l}\text { FARGO - Centre de } \\
\text { Recherche en Finance, } \\
\text { Architeture et Gouver- } \\
\text { nance des Organisations } \\
\text { (Complementar - Outras } \\
\text { bases) }\end{array}$ & $\begin{array}{l}\text { Corporate Governance Theo- } \\
\text { ries: From Micro Theories to } \\
\text { National Systems Theories }\end{array}$ & $\begin{array}{l}\text { Charreaux } \\
\text { (2004) }\end{array}$ \\
\hline Corporate Governance & $\begin{array}{l}\text { Shareholding Versus Stake- } \\
\text { holding: A Critical Review of } \\
\text { Corporate Governance }\end{array}$ & $\begin{array}{l}\text { Letza et al. } \\
(2004)\end{array}$ \\
\hline
\end{tabular}

Fonte: Elaborado pelos autores. 


\section{ANÁLISE}

\section{a. Perspectivas Teóricas em Governança Corporativa}

Nenhuma teoria ou modelo específico já aplicado seria suficiente para entender, avaliar ou estruturar a Governança Corporativa, devido principalmente ao comportamento diferenciado de cada ator (AL-BAIDHANI, 2014). As práticas de Governança requerem uma abordagem mais holística a partir de um quadro de referência contextualizado (FILATOTCHEV et al., 2013; FILATOTCHEV e BOYD, 2009). A literatura pede abordagens multidisciplinares (BROWN et al., 2011; FILATOTCHEV e BOYD, 2009) capazes de gerar dados que reflitam as condições locais sem focar em relações teóricas específicas, que podem não endereçar problemas reais, idiossincrasias e problemas de informação, em um ambiente extremamente complexo (DUHNFORD et al., 2008). Para Harris (2009) há a necessidade de pesquisas que utilizem múltiplas perspectivas em seu design, que tenham contribuição de diversas disciplinas e empreguem metodologias variadas.

Afza e Nazir (2014) relatam a dificuldade de uma definição comum, no mundo, em relação ao que envolve a Governança Corporativa. Verifica-se que apesar de diversas pesquisas já terem sido realizadas, os resultados empíricos não são conclusivos devido à falta da consideração do contexto (FILATOTCHEV e BOYD, 2009). A literatura sugere que é possível que os contextos organizacionais dentro de uma sociedade ou de um país sejam suficientemente semelhantes para que a pesquisa se dê neste nível (SHEN et al., 2016; FILATOTCHEV e BOYD, 2009). Sistemas de Governança nacionais são sistemas complexos com questões ignoradas pelas teorias mais tradicionais no campo da Governança Corporativa (CHARREAUX, 2004), como a Teoria da Agência, que olha os atores em sua racionalidade limitada (SIMON, 1947), com foco em explorar o conflito entre donos e administradores, ou donos majoritários e minoritários (SHEN et al., 2016). Brown et al. (2011) clamam por teorias que expliquem de forma complementar as práticas de Governança Corporativa. Os pesquisadores têm buscado explorar o uso de teorias diferentes das usualmente utilizadas na área, como: Teoria da Firma, Teoria do Custo de Transação, Teoria Politica e Sociológica, 
Teoria da Visão Baseada em Recursos, Teoria Institucional, Teoria dos Acionistas (shareholder), Teoria das Partes Relacionadas (stakeholder), Teoria do Procurador (stewardship) (BRENNAN e SOLOMON, 2008; PING e ANDY, 2011; AFZA e NAZIR, 2014; AL-BAIDHANI, 2014; SHEN et al., 2016; AHMAD e OMAR, 2016). São exploradas novas concepções e resultados para a Governança Corporativa, bem como contextos sociais específicos, como o das economias em desenvolvimento (AFZA e NAZIR, 2014; SHEN et al., 2016). Os incentivos e recursos disponíveis na Governança Corporativa de uma organização são concebidos em relação a um contexto particular, o qual define o comportamento gerencial por meio de normas e cognições compartilhadas, com as práticas em si estando relacionadas à configuração das variáveis organizacionais (FILATOTCHEV et al., 2013). Diversos artigos são influenciados pelo campo da sociologia (MCNULTY et al., 2013) e exploram o funcionamento e as interações entre os mecanismos de Governança Corporativa, a visão comportamental, as questões de poder e demais dimensões da sociologia (FILATOTCHEV e WRIGHT, 2017; SHEN et al., 2016). Teorias sobre o processo decisório (MCNULTY et al., 2013) revelaram os padrões e processos de sense-making (WEICK, 2005) e os processos sociais que ocorrem nas atividades dos Conselhos de Administração, a partir de uma abordagem qualitativa.

\section{b. Perspectivas Metodológicas em Governança Corporativa}

Prevalecia nas metodologias empregadas nas pesquisas na área uma perspectiva funcionalista, em que se buscava tornar mais eficientes os sistemas de Governança Corporativa. Os resultados dessa linha de pesquisas geralmente são prescritivos, centrados em definir 'o quê' constitui os problemas e 'como' se resolver os problemas de Governança Corporativa (YOUNG e THYIL, 2008). Os desenvolvimentos metodológicos subsequentes levaram à procura por um melhor entendimento do funcionamento e da evolução dos sistemas de Governança Corporativa, apontando a necessidade de aprimoramento dos aspectos epistemológicos e metodológicos (CHARREAUX, 2004). Abordagens de pesquisa alternativas começaram a investigar também o 'porquê' da ocorrência dos problemas de Governança Corporativa, como, por exemplo, as pesquisas que focam 
no processo de tomada de decisão ou em questões comportamentais em Governança (YOUNG e THYIL, 2008). Autores têm passado a pesquisar os processos ao invés dos resultados (FILATOTCHEV e BOYD, 2009). Para Shen et al. (2016), é importante pesquisar sobre a forma de pensar, sobre o conhecimento acumulado e como agem os atores em contextos específicos. A abordagem da sociologia organizacional pode permitir o melhor entendimento das relações que se dão na prática, considerando os mecanismos de Governança Corporativa e o contexto organizacional (FILATOTCHEV et al., 2013).

A metodologia deve permitir, além de um resultado prescritivo, uma maior função descritiva que permita se chegar a proposições teóricas sobre como as ações são realizadas e as decisões são tomadas (YOUNG e THYIL, 2008). Os métodos qualitativos são particularmente úteis para o estudo de contextos específicos, permitindo demonstrar como culturas e valores locais podem se diferenciar de modelos gerados em outros contextos (BRENNAN; SOLOMON, 2008). A Governança Corporativa das empresas evolui durante seus ciclos de vida, de modo que quadros de referência contextualizados gerados pela pesquisa qualitativa são mais adequados para a pesquisa na área, ao invés de modelos externamente pré-definidos (FILATOTCHEV et al., 2006). A pesquisa qualitativa também contribui para se repensar e desafiar premissas racionalistas ou significados pré-determinados sobre como agem os atores da Governança Corporativa (MCNULTY et al., 2013) e ajudar o desenvolvimento da teoria, permitindo acessar os relacionamentos e as influências que se dão no processo decisório (BRENNAN e SOLOMON, 2008; MCNULTY et al., 2013). Para MCNULTY et al. (2013), a maioria dos artigos que usa métodos qualitativos é exploratório ou busca o desenvolvimento de teoria, visto que os métodos qualitativos têm se mostrado mais efetivos na exploração de fenômenos novos ou na geração de novas ideias sobre fenômenos conhecidos. Os métodos qualitativos se revelam adequados para entender as práticas de Governança Corporativa tanto para o estudo no nível de grupos (como os Conselhos de Administração), quanto para as análises entre grupos (Conselhos de Administração versus gerentes no processo decisório) (Mcnulty et al., 2013). 
Em resumo, a literatura indica a necessidade de pesquisas de campo onde se interaja diretamente com os atores, que sejam voltadas para a prática e que investiguem interações e relacionamentos entre atores, de forma a explorar as estruturas e processos formais ou informais, dando atenção ao contexto e à dinâmica dos comportamentos (MCNULTY et al., 2013). O desenvolvimento de estudos que explorem além do que está no domínio público é considerado importante para garantir que a pesquisa não se afaste do fenômeno, não estudando a aparência, mas o conteúdo (MCNULTY et al., 2013). Por fim, encontra-se ainda na literatura o uso e recomendações para abordagens mais interpretativas para a pesquisa em Governança Corporativa (BRENNAN e SOLOMON, 2008), as quais são adequadas para a análise das atividades e processos dos Conselhos de Administração, que são de natureza multi-dimensional (MCNULTY et al., 2013). Um exemplo de estudo na área de Governança Corporativa que busca entender os diferentes níveis e definições existentes nas funções de Governança Corporativa (estruturas, sistemas, padrões para controle), de gestão (processos e procedimentos) e na prática (alinhamento de ações e resultados às políticas e aos padrões) é o estudo de Brennan e Flynn (2013).

\section{DisCuSSÃo Dos RESUltados}

É consistentemente demonstrada uma preocupação com a resolução dos problemas vividos e a possibilidade de se encontrar novas soluções com aplicação de abordagens teórico-metodológicas ainda não exploradas no campo, a partir de métodos qualitativos e interpretativos, revendo modelos, métodos e teorias, aprofundando e consolidando um novo arcabouço teórico, baseado em uma ontologia relacional e uma epistemologia interpretativa, que explore disciplinas mais relacionadas aos aspectos das relações, do comportamento humano e considerando contribuições da sociologia.

Atendendo a essas proposições de pesquisadores do campo, foi possível notar que a Governança Corporativa tem começado a ser pesquisada e teorizada por lentes mais voltadas para a racionalidade prática (SANDBERG e TSOUKAS, 2011), com uma ontologia relacional e uma epistemologia interpretativa, explorando dimensões ainda pouco estudadas em Governança Corporativa. 
As propostas para melhoria dos sistemas de Governança Corporativa vinham tendo como foco, em geral, novos arcabouços regulatórios, novos processos de tomada de decisão ou novas formas de aprendizagem (YOUNG e THYIL, 2008), bem como incursões de pesquisa frequentes em países de economias emergentes, de modo a testar a generalização e padronização possível dos sistemas de Governança Corporativa em culturas e contextos sociais específicos. No entanto, a preocupação com os problemas identificados nas organizações relacionados a falhas nos sistemas de Governança têm levado os pesquisadores a explorarem por diversos ângulos o tema. Em sua revisão na literatura, Young e Thyil (2008) relatam pesquisas que indicam efeitos complexos dos sistemas de Governança no comportamento dos atores, e que para superar os problemas encontrados com o aumento dos controles nas organizações - tais como a lentidão nos processos, a falta de criatividade e a falta de confiança (DURDEN e PECH, 2006) - devem-se buscar sistemas menos prescritivos e formais para a prática da Governança. Para Young e Thyil (2008, p. 103), “tem sido demonstrado que o sistema de Governança é um 'sistema vivo' e um 'sistema aberto'".

Neste sentido, a partir do reconhecimento de que os pesquisadores têm clamado por novas perspectivas teóricas e novos modelos para a Governança Corporativa, Young e Thyil (2008) defendem que é preciso ir além da visão de controles e que uma visão integrada é necessária para o entendimento dos sistemas de Governança Corporativa. Assim, os autores propõem um novo modelo de Governança Corporativa, o qual chamam de holístico, que amplia as dimensões consideradas pelos sistemas de Governança para além das questões legais e regulatórias, incluindo discussões sociológicas, éticas, sobre gestão de pessoas, comportamental, além de um foco nas dimensões internas das organizações, em adição ao foco em atender aos requisitos externos, sejam regulatórios, do mercado financeiro, dos acionistas, das demais partes relacionadas, como as comunidades impactadas, entre outros. $\mathrm{O}$ atendimento aos requisitos impostos externamente tem sido o objeto principal dos sistemas de Governança.

Young e Thyil (2008) afirmam também que a inter-relação entre diversas dimensões específicas da organização, tais como o estágio no ciclo de vida da empresa, o ambiente operacional e a estrutura 
proprietária impactam na Governança e devem ser estudados de uma maneira mais interpretativa.

Outra dimensão a ser aprofundada por novas abordagens é a ética. $\mathrm{O}$ complexo mundo organizacional também exige que questões éticas e valores locais, que complementam a lei e as regras no estabelecimento da boa Governança, sejam estudadas por uma abordagem mais interpretativa a partir do comportamento dos atores (YOUNG e THYIL, 2008). Os códigos de ética são interpretados pelos atores, hermeneuticamente e eticamente, e ganham significados, resultando em ações, ou seja, sendo apropriados pela prática, se constituindo como um quadro de referência dinâmico, contribuindo para o avanço de uma cultura ética (MERCIER e DESLANDES, 2017). Assim, as pesquisas devem buscar explorar a racionalidade prática (SANDBERG e TSOUKAS, 2011) em relação a este mecanismo de Governança ao invés de se focar somente nos códigos de ética. Nesse sentido, a busca pelos significados dados e pelas experiências, a partir dos relatos de segunda ordem, pode ser acessada pela abordagem fenomenográfica (MARTON, 1986; 1981; MARTON e BOOTH, 1997).

A falta de comunicação, de relacionamento entre os atores e o silêncio resultante pela falta de confiança, também se constituem como uma dimensão que não pode ser tratada por abordagens focadas em regras, controles e conformidade, mas por abordagens que busquem acessar processos informais de Governança e requisitos de integridade (VERHEZEN, 2010; CALDAS; TAMBOSI-FILHO; VIEIRA, 2014). Esses processos informais podem ser acessados pelas narrativas das experiências vividas (VERHEZEN, 2010), o que também torna a fenomenografia uma abordagem propícia.

Young e Thyil (2008) ainda afirmam que as ações dos atores são impactadas pelo próprio processo de tomada de decisão. Assim, explorar a dinâmica própria do processo de tomada de decisão e as estruturas decisórias do ponto de vista comportamental, reconhecendo que ele é realizado por pessoas, pode contribuir para o entendimento do papel e das atividades do Conselho de Administração e para a proposição de sistemas de Governança mais robustos.

As implicações da Governança Corporativa para a gestão interna e para a prática poderão emergir como uma nova categoria 
da literatura de Governança Corporativa (HARRIS, 2009). Considerando todo o exposto, Young e Thyil (2008) clamam por uma Teoria de Governança que seja uma Teoria Dinâmica de Governança, que contenha uma gama maior de variáveis, umas controláveis e outras determinísticas. Nesta linha é que se desenvolve uma nova visão para a Governança Corporativa e para a qual se propõe aqui a fenomenografia como abordagem teórico-metodológica pertinente.

\section{UMA Nova ABordagem TeÓRICO-METOdológica PARA A Governança CoRPorativa}

A abordagem fenomenográfica, como uma abordagem qualitativa e interpretativa, tem como objetivo o acesso a experiências e interações em seu contexto natural (DENZIN e LINCOLN, 2005). Nos últimos anos, a fenomenografia vem se constituindo como uma abordagem de pesquisa alternativa para o estudo das práticas organizacionais. Tem como princípio explicitar as maneiras pelas quais as pessoas percebem e vivenciam um fenômeno, o que contribui para explicar as questões organizacionais e cria novas possibilidades de se gerar teoria (ROCHA-PINTO et al., 2018). Segundo Sandberg e Tsoukas (2011), o método nos dá a oportunidade de diminuir a distância entre as teorias que são criadas e a prática nas organizações, onde é mais complexa, possibilitando analisar a relação entre a ação e os objetos materiais na constituição das práticas organizacionais (ROCHA-PINTO et al., 2018). Para Rocha-Pinto et al. (2018, p.8), "além de ser uma abordagem que propõe a construção de teoria a partir da prática, a fenomenografia tem como objetivo, também, servir a alguma transformação da prática estudada".

É uma abordagem qualitativa e interpretativa utilizada para compreender a prática com base nas percepções que as pessoas têm dos fenômenos organizacionais em que participam, e não a partir da observação e interpretação do pesquisador (COLLIER-REED; INGERMAN, 2013; VIEIRA; RIVERA, 2012).

Na pesquisa fenomenográfica, não são aplicados modelos teóricos pré-definidos, o que faz desta abordagem uma abordagem que tem condições de atender aos anseios do campo da Governança Corporativa, o qual busca novas teorias para a área. 
Ao final, o método permite gerar proposições teóricas a partir de uma confrontação dos resultados da pesquisa com as teorias existentes, o que irá contribuir para o desenvolvimento da teoria da área e também para a prática organizacional, gerando um arcabouço teórico mais abrangente para o campo da Governança Corporativa.

\section{a. A Pertinência da Fenomenografia para a Governança Corporativa}

\section{a.1 Teórica}

Os estudos de Governança Corporativa pela lente da Teoria Institucional (SCOTT, 2004), por exemplo, expandem o olhar, da esfera micro, onde o foco é o ator, para a esfera macro, onde o foco são os mecanismos regulatórios, normativos e cognitivos. Estes passam a serem os portadores de identidades, interesses e coalisões que selecionam e adaptam práticas socialmente legitimadas por fatores culturais, sociais ou políticos, e acessíveis organizacionalmente. No nível macro, é possível defender que no campo da Governança Corporativa é necessária uma abordagem de sistema aberto, que considere as influências externas, tendo em vista a diversidade, as flutuações, as incertezas e os ambientes sociais específicos de cada empresa. A fenomenografia possibilita esta abordagem ao desbravar as concepções locais considerando suas influências, como requer a literatura de Governança (FILATOTCHEV et al., 2013). Em linha com Shen et al. (2016), a abordagem teórico-metodológica que se propõe, a fenomenografia, pode fornecer ainda uma contribuição para o entendimento da forma de pensar, do conhecimento acumulado e de como agem os atores em contextos específicos. Por meio de seu 'Espaço de Resultado', a fenomenografia constrói, interpreta e ilustra as concepções e significados dos atores. O Espaço de Resultado da fenomenografia é um quadro de referência contextualizado capaz de acessar os mecanismos internos do processo de Governança e vislumbrar os entendimentos coletivos, conforme solicitado por Filatotchev et al. (2013) e Filatotchev e Boyd (2009), a partir de uma perspectiva de segunda ordem. Isto é, baseada nos significados que os atores atribuem e na variação das suas experiências com o fenômeno. 
Assim, a fenomenografia pode acessar as normas e cognições compartilhadas (FILATOTCHEV et al., 2013). Enquanto a Teoria Institucional verifica como o contexto determina o ambiente e as ações, a fenomenografia, por sua vez, irá permitir entender as variações nas concepções coletivas existentes sobre o fenômeno, se constituindo como uma abordagem interpretativa mais prática e abrangente para a pesquisa em Governança Corporativa.

Desta forma, a fenomenografia atende aos requisitos de Filatotchev et al. (2013) quanto ao entendimento das relações e comportamentos, bem como permitindo um melhor entendimento dos resultados do processo de Governança, considerando o sistema de Governança e o contexto da organização, localizado no tempo e espaço, sendo uma abordagem mais voltada para os processos.

A fenomenografia é uma abordagem que permanece aberta à possibilidade de uso de diversas teorias para discussão dos resultados da pesquisa empírica. Ainda que neste método se utilize na fase inicial teorias para definir a área substantiva que circunda a problemática da pesquisa, neste método não se definem modelos teóricos para aplicação em campo, permitindo observar o que precisa ser observado sem necessidade de enquadrar em modelos existentes. O Espaço de Resultado na fenomenografia surge, então, como uma contribuição teórica que se dará pela discussão dos achados vis-à-vis às teorias mais diversas e apropriadas a cada caso. Dessa forma, está aberta a uma abordagem teórica multidisciplinar para o problema a partir do que o campo apontar como recurso teórico para discussão, atendendo a Ahmad e Omar (2016), Brown et al. (2011), Filatotchev e Boyd (2009), Harris (2009) e Duhnford et al. (2008).

Considerando que os contextos organizacionais, no que tange aos sistemas de Governança Corporativa, sejam semelhantes em um país, o Espaço de Resultado gerado pela pesquisa fenomenográfica poderá ser replicado para uso em diferentes empresas pertencentes ao mesmo contexto de sociedade e país, em linha com Shen et al. (2016) e Filatotchev e Boyd (2009).

\section{a.2 Metodológica}

Neste método, há um aumento do contato do pesquisador com o fenômeno, que é um requisito da fenomenografia, e pode ser con- 
siderado um dos fatores que contribui para o melhor entendimento do fenômeno e, assim, para a teorização a seu respeito. O pesquisador fenomenográfico estuda o conteúdo, interagindo direto com os atores do processo, acessando processos formais e informais, de forma contextualizada e de acordo com sua dinâmica, o que atende às lacunas apontadas por Mcnulty et al. (2013). Além disso, a fenomenografia é um método que fornece resultados contextualizados e desvenda premissas e significados locais, o que atende às necessidades apontada por Filatotchev et al. (2006).

A fenomenografia também explora por meio de entrevistas semiestruturadas os significados concebidos pelos atores do processo, nesse caso se mostrando particularmente pertinente às observações levantadas por Brennan e Flynn (2013) e Brennan e Solomon (2008).

O foco no comportamento, conforme requerido pela literatura (MCNULTY et al., 2013), também é acessível por meio do relato das experiências na fenomenografia, permitindo o debate prático e teórico em uma abordagem que busca as concepções coletivas, no nível de grupos atuantes em um mesmo fenômeno, para teorizar sobre o processo decisório dos Conselhos de Administração, como estudado por Smith et al. (2011).

Enfim, considerando a importância de se identificar e se descrever as concepções e as dimensões com base nos significados dados pelos atores, a fenomenografia permite considerar contextos específicos por meio das concepções locais. Além disso, é uma abordagem teórico-metodológica que permite explorar diferentes atores e apresentar mais de uma visão. Pode, ainda, por exemplo, estar vinculada à exploração de documentos do Conselho de Administração em complemento às entrevistas (SMITH et al., 2011; FILATOTCHEV e WRIGHT, 2017). Permite também tratar a Governança Corporativa como um processo, pondo-a em linha com os requisitos de Filatotchev e Wright (2017). Por tudo isso, a fenomenografia se constitui como um método recomendado para a pesquisa em Governança Corporativa que atende aos principais anseios da literatura.

Adicionalmente, o teste das teorias ainda é um objetivo pouco explorado em Governança Corporativa quando utilizados métodos qualitativos. O resultado da fenomenografia, seu Espaço de Resultado, é aplicável nas organizações (SANDBERG, 2000) podendo 
gerar contribuições úteis para outras organizações. Sendo assim, é um método que pode contribuir para o desenvolvimento da teoria em Governança Corporativa e para replicação e generalização, considerando contextos semelhantes. Modelos teóricos de Governança, como o de Young e Thyil (2008) - que é mais abrangente, contendo, além dos controles, as dimensões internas e externas, as dimensões comportamentais e as relacionadas ao processo decisório - podem ser discutidos frente ao Espaço de Resultado, de modo a contribuir também para a evolução da teoria nessa perspectiva.

A fenomenografia pode contribuir decisivamente para o entendimento de como as decisões são tomadas, possibilitando acessar uma gama hierarquizada de explicações de segunda ordem, isto é, providas pelos atores que vivenciam processo, e que se constituem como ponto de partida para descrever e explicar o fenômeno em sua complexidade. Embora a generalização não seja o objetivo da pesquisa qualitativa interpretativa, é um caminho possível de ser explorado e que poderá trazer benefícios ainda não disponíveis para a pesquisa que tem como base outros métodos mais tradicionais.

\section{Considerações Finais}

A revisão de literatura sobre o estado da arte da pesquisa permitiu destacar as principais tendências da teoria e do método aplicado em Governança Corporativa. Ficou explícita a recorrente indicação da necessidade de abordagens considerado o uso de teorias mais diversas e métodos qualitativos e interpretativos, no intuito de explorar e descrever sistemas abertos e dinâmicos.

Nesse sentido, defende-se que a fenomenografia é uma abordagem teórico-metodológica indicada para explorar as questões ainda em aberto que se apresentam na área de Governança Corporativa, com destaque para os aspectos comportamentais, de relacionamento e também a exploração de contextos específicos. Em suma, são os aspectos relacionados à prática, em toda a sua complexidade, que podem ser compreendidos a partir das concepções coletivas acerca do fenômeno e estruturadas no Espaço de Resultado fenomenográfico.

Essa nova abordagem poderá contribuir para o avanço dos sistemas de Governança Corporativa em países em desenvolvimento, 
com suas especificidades e culturas particulares, bem como para os sistemas de Governança Corporativa em todo o mundo, a partir de uma visão da Governança como um sistema contextualizado, aberto e dinâmico.

Assim, acredita-se, a fenomenografia atende aos anseios presentes na literatura por pesquisas de perfil interpretativo, que constituam novas abordagens para a área, e possibilitem expandir as fronteiras teórico-metodológicas do campo.

Sugere-se, portanto, o uso da fenomenografia como uma abordagem teórico-metodológica a ser explorada em estudos futuros de Governança Corporativa. Além do potencial de originalidade presente na abordagem fenomenográfica, é importante destacar também sua propensão à utilidade prática dos resultados da pesquisa em Governança Corporativa, podendo trazer novas ideias e contribuir para as empresas ao fornecer um resultado que considera fundamentalmente o contexto.

\section{REFERÊNCIAS}

AFZA, T.; NAZIR, M. S. Theoretical Perspective of Corporate Governance: A Review. European Journal of Scientific Research, v. 119. n. 2, p. 255-64, 2014.

AHMAD, S.; OMAR, R. Basic corporate governance models: a systematic review. International Journal of Law and Management, v. 58, n.1, p. 73-107, 2016.

AL-BAIDHANI, A. M. Review of Corporate Governance Bundle. Universiti Putra Malaysia, 2014.

BRENNAN, N. M.; SOLOMON, J. Corporate Governance, Accountability and Mechanisms of Accountability: An Overview. Accounting, Auditing and Accountability Journal, v. 21, n. 7, p. 885-906, 2008.

BROWN, P.; BEEKES, W.; VERHOEVEN, P. Corporate governance, accounting and finance: A review. Accounting and Finance, v. 51, p. 96-172, 2011.

CALDAS, C. B.; TAMBOSI FILHO, E.; VIEIRA, A. M. Governança Corporativa e Sustentabilidade: uma relação necessária. Revista UNIABEU, v. 7, p. 353-369, 2014.

CHARREAUX, G. Corporate Governance Theories: From Micro Theories to National Systems Theories. FARGO - Centre de Recherche en Finance, Architecture et Gouvernance des Organisations, 2004.

COLLIER-REED, B.; INGERMAN, Å.. Phenomenography: From critical aspects to knowledge claim. In Theory and method in higher education research, Emerald Group Publishing Limited, p. 243-60, 2013. 
DENZIN, N. K ; LINCOLN, Y. S. The sage handbook of qualitative research, 3rd ed. Thousand Oaks, CA: Sage, 2005.

DUHNFORD, A. M.; KLEIN, C.; LAMPENIUS, N. Theoretical Foundations of Corporate Governance Revisited: A Critical Review. Corporate Ownership; Control, v. 6, n. 2, 2008.

DURDEN, C.; PECH, R. The increasing cost of corporate governance: decision speed-bumps for managers. Corporate Governance: The international journal of business in society, v. 6, n. 1, p.84-95, 2006.

FILATOTCHEV, I.; BOYD, B. K. Taking Stock of Corporate Governance Research While Looking to the Future. Corporate Governance: An International Review, v. 17, n. 3, p. 257-65, 2009.

FILATOTCHEV, I.; JACKSON, G.; NAKAJIMA, C. Corporate governance and national institutions: A review and emerging research agenda. Asia Pacific Journal of Management, v. 30, p. 965-86, 2013.

FILATOTCHEV, I.; WRIGHT, M. Methodological issues in governance research: An editor's perspective. Corporate Governance: An International Review, v. 25, p. 454-60, 2017.

HARRIS, J. E. A review of Latin American corporate governance literature: 2000-2009. Corporate Governance: The international journal of business in society, v. 9, n. 5, p. 635-48, 2009.

MARTON, F.. Phenomenography: Describing conceptions of the world around us. Instructional Science, v. 10, p. 177-200, 1981.

MARTON, F. Phenomenography - A research approach to investigating different understandings of reality. Journal of Thought, v. 21, n. 3, p. 28-49, 1986.

MARTON, F. e BOOTH, S. A. Learning and Awareness. Mahwah: Lawrence Erlbaum Inc., 1997.

MCNULTY, T.; ZATTONI, A.; DOUGLAS, T. Developing Corporate Governance Research through Qualitative Methods: A Review of Previous Studies. Corporate Governance: An International Review. v. 21 n. 2, p. 183-98, 2013.

MERCIER, G., DESLANDES, G. There are no Codes, Only Interpretations. Practical Wisdom and Hermeneutics in Monastic Organizations. Journal of Business Ethics, v. 145, n. 4, p.78194, 2017.

PING, Z.; ANDY, C. W. W. Corporate Governance: A Summary Review on Different Theory Approaches. International Research Journal of Finance and Economics, n. 68, 2011.

ROCHA-PINTO, S. R.; JARDIM, L. S.; BROMAN, S. L. de S.; GUIMARÃES, M. I. P.; TREVIA, C. F.. Fenomenografia e Prática nas Organizações: A Contribuição da Fenomenografia para os Estudos Organizacionais Baseados na Lente da Prática. In ENANPAD, 2018, Curitiba.

SANDBERG, J. Understanding Human Competence at Work: An Interpretative Approach. The Academy of Management Journal, v. 43, n. 1, p. 9-25, 2000.

SANDBERG, J.; TSOUKAS, H. Grasping the logic of practice: theorizing through practical rationality. Academy of Management Review, v. 36, n. 2, p. 338-60, 2011.

SCOTT, W. R.. Institutional theory. In: Ritzer, George. Encyclopedia of Social Theory. 1st ed. Thousand Oaks, CA: Sage, p. 408-14, 2004. 
SHEN, W.; Zhou, Q.; Lau, C. Empirical Research on Corporate Governance in China: A Review and New Directions for the Future. Management and Organizational Review, v. 12, n. 1, p. 41-73, 2016.

SIMON, H. Administrative behavior: A Study of Decision-making Processes in Administrative Organization, 1st ed., New York: The Macmillan Company, 1947.

SMITH, P., DUFOUR, Y., ERAKOVIC, L. Strategising and the routines of governance: An empirical analysis of practices in an international engineering consultancy firm. Asia-Pacific Journal of Business Administration, v. 3, n. 2, p.149-64, 2011.

WEICK, K., SUTCLIFFE, K. M..; OBSTFELD, D. Organizing and the process of sense-making. Organization Science, v. 16, n. 4, p. 409-21, 2005.

YOUNG, S., THYIL, V. A holistic model of corporate governance - a new research framework. Corporate governance: the international journal of business in society, v. 8, n. 1, p. 94-108, 2008.

VERHEZEN, P. Giving Voice in a Culture of Silence. From a Culture of Compliance to a Culture of Integrity. Journal of Business Ethics, v. 96, n. 2, p.187 - 206, 2010.

VIEIRA, A. M.; RIVERA, D. P. B. A Hermenêutica no Campo Organizacional: duas possibilidades interpretativistas de pesquisa. Revista Brasileira de Gestão de Negócios, v. 14, n. 44, p. 261-273, 2012.

Recebido em: 22-5-2019

Aprovado em: 12-11-2020

Avaliado pelo sistema double blind review.

Disponível em http://mjs.metodista.br/index.php/roc 